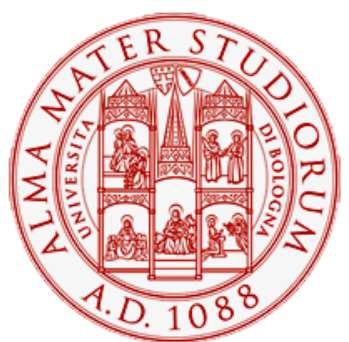

Alma Mater Studiorum - Università di Bologna DEPARTMENT OF ECONOMICS

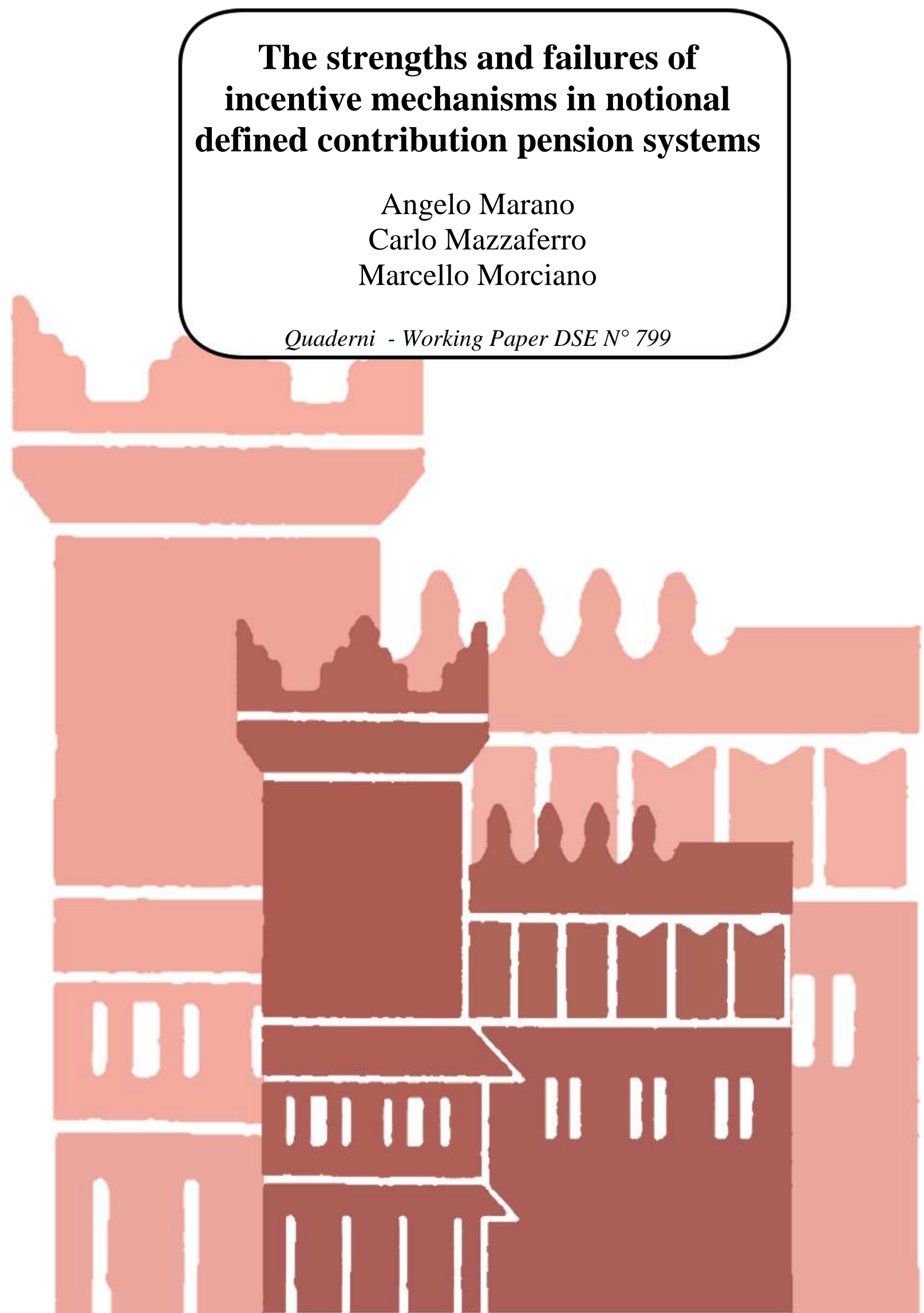




\title{
The strengths and failures of incentive mechanisms in notional defined contribution pension systems
}

\author{
Angelo Marano ${ }^{\S}$
}

(Italian Ministry of Labor and Social Affairs,amarano@welfare.gov.it),

\author{
Carlo Mazzaferro \\ (Department of Economics, Bologna University and CAPP, \\ carlo.mazzaferro@unibo.it),
}

\begin{abstract}
Marcello Morciano
(Health Economics Group, University of East Anglia, Norwich and Institute for Social, CAPP and Economic Research, University of Essex, Colchester, UK, m.morciano@uea.ac.uk)
\end{abstract}

First draft: June 2011. This version: 23 November 2011

Comments welcomed!

$\S$ Corresponding author. 


\begin{abstract}
Public pension systems based on the Notional Defined Contribution (NDC) principle were introduced during the '90s in Italy, Sweden and Poland, among other countries. They mimic private savings, in that individuals get back, as pensioners, what they contributed to social security during working life, plus returns. As such, NDC systems should realize actuarial equity and incentive neutrality. However, when one considers the presence of NDC pensions together with minimum and social assistance pensions, this is no longer true. Indeed, in all the three countries considered, the NDC system shows a regressive feature, which disincentivizes contributions, particularly from low earners, who would be better off entering, or staying in, the shadow economy.

In order to reduce the extent of this phenomenon, we examine the effects of introducing, or increasing, the possibility of accumulation of social assistance and NDC pensions, which would also improve pension adequacy. A complete accumulation of the two would solve the incentive problem, but would be costly and would require a structural reform of the pension system financing mechanism, altering the current balance between social contributions and general fiscal revenues. We show the effects of a change in the cumulation rules for social assistance and NDC pensions in Italy using CAPP_DYN, a population-based dynamic microsimulation model, which allows assessment of the evolution of the pension system in the coming decades and the distributional implications of such reform.
\end{abstract}

Keywords: public pension systems, minimum pension, dynamic microsimulation

JEL: H55, J26, C51

\title{
Index
}

1. Introduction

2. The NDC principle, actuarial equity, incentive neutrality and automatic balance of expenditure and revenues

3. Social assistance minimum pensions in current NDC systems

4. A microsimulation analysis

5. Increasing accumulability of social assistance and NDC pensions

6. Conclusions and future work

References 


\section{The strengths and failures of incentive mechanisms in notional defined contribution pension systems}

\section{Introduction}

Pension systems based on the Notional Defined Contribution principle (henceforth NDC) ${ }^{1}$ were firstly introduced in Italy (1995), Sweden (1994-1998), Latvia (1995-1996) and Poland (1999) as major, structural, reforms of their public pension systems. After fifteen years in operation, during which NDC has been gradually better understood at the international level, somehow it is becoming almost "fashionable", so that several other countries adopted it, or are discussing whether to go in such direction ${ }^{2}$.

However, there are still misunderstandings about the nature of NDC systems, their main advantages and shortcuts. While analyses and discussions can be easily found in the academic literature and in the websites of international organizations (Holzmann and Palmer 2006, Queisser and Whitehouse 2006, Whitehouse 2010), nevertheless most of the attention has been devoted to the flexibility of the design, to the presence of mechanisms of automatic adjustment of expenditure and contribution revenues, to the best way of taking care of increases in life-expectancy and to how guarantying pension adequacy. Instead, issues like the effectiveness of the incentive structure to contribute in a NDC system and its actuarial fairness have been receiving little attention: they are considered as embedded in the Defined-Contribution (DC) formula, and, at best, analysis has been made just comparing NDCs with Defined-Benefit (DB) private pension funds.

In such a framework, we are not aware of any contribution dealing with the issue we examine in this paper: the failure of NDC systems to guarantee actuarial equity and incentive neutrality when the interaction of NDC and social assistance pensions ${ }^{3}$ is considered. Indeed, in presence of social assistance, low-wage workers, or those who experience intermittent employment histories, could decide that it is not worth for them to contribute to the pension system, as their NDC pension entitlement will not be larger than the social assistance minimum they would be entitled anyway. Furthermore, people that will end up with NDC pensions greater than social assistance endowments, could nevertheless find themselves not much better-off than those who receive social assistance or, at least, not so much as the contributions they paid would justify. An incentive failure similar to the one that characterizes poverty and unemployment traps arises, with a distinctive feature, in this case, that no activation policies can be implemented.

As said, this paper discusses the problem of effectiveness of the incentive structure of NDC pension systems, in particular at low wage levels. Section 2 briefly reviews some of the main features and strengths of NDC systems; section 3 considers the interaction of the NDC pensions together with social assistance and minimum pensions in Italy, Sweden and Poland. In section 4 we study the relevance of the incentive neutrality and actuarial equity problems in Italy for the coming decades using CAPP_DYN, one of the most advanced dynamic population-based microsimulation model in the EU (TARKI 2008). In section 5 we use the model to evaluate the effects of increasing the possibility to accumulate social assistance and NDC pensions; we then discuss two alternative

\footnotetext{
* The opinions expressed in this paper are those of the authors and cannot be attributed to any institution.

${ }^{1}$ The same systems are also sometime referred to as non-financial defined contribution. While we prefer the label "notional" to "non-financial", the meaning does not change, as well as the acronym.

${ }^{2}$ Among others, the Kyrgyz Republic, Mongolia, Russia and Egypt have introduced NDC elements in their pension systems. Spain, China and Belarus have been examining the possibility to do so. Also, the comparison of traditional pension systems with NDCs stimulated the introduction in the former of mechanisms that replicate some of the features of NDCs (Whitehouse 2010).

${ }^{3}$ Or, as in the case of Poland, of NDC pensions and minimum social security pensions (see below, section 3 ).
} 
policy options: allowing full accumulation of the two, or rather, introducing a social security minimum pension, which is length-of-service dependent. Section 6 concludes.

\section{The NDC principle, actuarial equity, incentive neutrality and automatic balance of expenditure and revenues}

NDCs are public pension systems that, operating on a pay-as-you-go (PAYG) basis, adopt a DC pension formula, built around actuarial principles which mimic private savings. In other words, although workers' social contributions are not put aside, notional (i.e. virtual) individual accounts are built, where each worker contributions are credited till retirement, getting a return which is in line with the growth rate of total contributions in the economy. Upon retirement, the accumulated, notional, capital is converted into a pension multiplying the accredited capital by age-specific annuity coefficients, which are built on the same actuarial principle as of private pensions' ones.

Formally, pensions in a NDC system are calculated as: $P^{N D C}=\varepsilon M C$, where $\varepsilon$ is the retirement age-specific coefficient (inversely related to the expected life-expectancy at retirement), while the (notional) pension savings is $M C=\sum_{\mathrm{i}=1}^{\mathrm{L}} \alpha w_{i}(1+\delta)^{L-i+1}$, with $w_{i}=$ wage in the $\mathrm{i}^{\text {th }}$ year of work, $\alpha=$ contribution rate, $L=$ length of service and $\delta=$ return rate on pension contributions which is typically set at the growth rate of total wages or GDP.

The advantages of NDC, with respect to the public DB systems they are typically going to replace, concern both the micro and macro aspects of pension policies (Holzmann and Palmer 2006).

As far as the microeconomic aspects are concerned, the NDC building principle should imply, on the one hand, a certain (actuarial) equity among individuals and, on the other, incentive neutrality with respect to the retirement age, the age of exit from the labor market and the work leisure (or working in the formal - informal sectors of the economy) individual's choice.

As for actuarial equity, each year all workers get the same rate of return on their contributions, although the return rate may vary year by year. Thus, NDC systems do not redistribute resources among retirees, nor they prize more particular categories of workers or types of careers, as DB systems generally $\mathrm{do}^{4}$. Moreover, as NDC systems aim at giving back to individuals just what they put in the system (plus returns, net of administrative costs), provided the annuity coefficients are computed accordingly to sound actuarial techniques, they attain incentive neutrality ${ }^{5}$. Firstly, neutrality with respect to the retirement age is granted. That is because a later retirement implies that the notional pension saving will be multiplied by an higher annuity coefficient, which takes into account a lower life-expectancy, while new contributions will be credited to her/his account together with further returns on past contributions, which will be given

\footnotetext{
${ }^{4}$ We define actuarial equity as a situation where people have equal internal rate of returns on their contributions, which (under some additional assumptions on the time horizon and the type of career considered) is guaranteed in NDCs through the provision that each year an equal rate of return applies to every contributions (and to all pension savings accrued in the virtual individual accounts). While actuarial equity compares individuals, incentive neutrality deals with how social contributions affects individual's behavior, typically comparing the internal rate of return on contributions with an outside return.

${ }^{5}$ It is important to notice that this neutrality only holds at the aggregate level, as it does not generally take into account gender differences in life-expectancy, as well as differential mortality risks according to individual socio-economic and health statuses (Mazzaferro, Morciano and Savegnago 2011).
} 
back as future pension. Secondly, NDC systems are also neutral with respect to the choice of exit from the labor market, providing positive effects in labor market flexibility. In fact, an individual could claim her/his pension while still remaining at work, without this implying a redistribution in favor or against her/him. Finally, as contributions are given back to individuals once retired, they enter in the individual's life-time optimization problem as compulsory saving, not as taxes; thus, they do not distort individual's choice about labor and leisure or about working in the formal sector or in the shadow economy, at least as long as compulsory social contributions do not exceed her/his saving needs and the analysis takes into account the difference on return rates recognized on private savings (the market rate) and on NDC contributions (the rate of growth of total wages or GDP) ${ }^{6}$.

As far as the macroeconomic aspects are concerned, NDCs embed automatic adjustment mechanisms, which guarantee the equilibrium among pension expenditure, contribution revenues and the respective rates of growth. Such mechanisms rely, on one side, upon the link between the return rate offered on contributions and the growth rate of total earnings ${ }^{7}$ and, on the other, on the update of annuity coefficients to changes in life-expectancy ${ }^{8}$. This, however, does not imply that in a NDC system the entire pension expenditure should be financed only through social contributions: general fiscal revenues could still be needed, in particular (and with relevance for our discussion) in order to finance social assistance programs, as well as to guarantee the accumulation of pension rights in case of spells of unemployment or training, sickness and maternity leaves.

It is remarkable that all of the above positive feature of the NDC system would be attained without the need to change the way of financing pension expenditure, i.e. avoiding the extra-burden that any shift from a PAYG to a fully funded system would entail in terms of greater taxation during the entire transition phase (first generation problem). Aside all these nice features, however, there is also some costs.

Firstly, generally NDCs appear less generous than the previous DB systems, which rises concern about future pensions' adequacy. This derives, on the one hand, from the specific parameters used in the old and the reformed systems and, on the other, from the fact that, while in the old systems typically only wages in years close to the career end or "best wages" in the entire working-life were considered in the pension formula, NDCs give equal weigh to all wages the individual received in her/his working-life, so that lower wages at the beginning of the career, or occasional drops of income, directly affect the amount of benefits.

Secondly, the automatic adjustment of expenditure to social contribution revenues in NDCs is pursued through a risk shift of both demographic and economic risks upon individuals, which was not present in the previous DB systems and it is not necessarily efficient from an insurance theory point of view. Indeed, in NDCs only longevity risks after retirement remain collectivized, all other risks being individualized (Marano 2006).

\footnotetext{
${ }^{6}$ Indeed, on this basis one could question the inclusion in the tax wedge of compulsory social contributions to a NDC system, which, however, would have strong implications for international comparisons.

${ }^{7}$ This implicitly assumes either equal contribution rates for all workers or a constant composition of the work force among different categories of workers. Furthermore, when, as in the Italian case, the NDC return rate is based on the GDP growth rate, underlying there is an assumption that real wages evolve in line with labor productivity.

${ }^{8}$ While it is often argued that NDCs are just a particular case of traditional DB systems, where wages during the entire career are considered in the calculation of pensionable earnings, the two show important differences. In particular, traditional DB systems insure most of the risks and do not embed automatic adjustment mechanisms, while NDCs attain the result of automatic adjustment of expenditure to contribution revenues mostly shifting risks from the public to the individual. It follows that, contrarily with what is sometime argued (OECD 2007), any equivalence between the two systems in terms of benefits delivered can only be verified ex-post (given the actual course of the economy and the demography), not ex-ante. It is also true, however, that German-type pension-point systems, traditionally classified as DBs, can also embed automatic adjustment mechanisms.
} 
Finally, as NDC systems give equal weight to all wages earned by an individual, a crucial (Pigouvian) incentive mechanism embedded in traditional DB systems, which prizes individual effort and dynamic career, disappears. Thus, if it has the advantages of eliminating a regressive redistribution mechanism on one hand, it produces clear disadvantages in term of promotion of workers' effort on the other hand.

\section{Social assistance minimum pensions in current NDC systems}

\subsection{How things change in presence of social assistance minimum pensions}

The literature analyzing the pros and cons of NDC systems (see references above) generally implicitly assumes NDC pensions rich enough to not interfere with social assistance provisions. However, this should not be taken for granted and hides what we believe is probably the most critical incentive problem in NDC systems: the failure to deliver actuarial equity and incentive neutrality in presence of non-contributory, social assistance, minimum pensions which cannot be fully cumulated with the contributory ones.

Indeed, depending on the institutional setting, it is possible that low earners will end up with a contributory NDC pension which is lower, or not much greater, that the social assistance minimum they would get anyway, in absence of other sources of income. If that is the case, the payment of social contributions would originate zero, or very low, returns when the amount of social assistance benefits is taken into account in running intertemporal analysis. An incentive failure similar to the one that characterizes poverty and unemployment traps arises (Employment Committee 2003, Carone et al. 2004), with a distinctive feature, in this case, that activation policies cannot be used, as social assistance pensions are aimed at setting a minimum standard of leaving for all the elderly and, as such, the only conditionality that can be considered is the means-test.

In this section we analyze this problem with reference to the institutional settings and the pension system parameters of three main EU countries that adopted the NDC system in the '90s: Italy, Sweden and Poland; the situation is represented in Figures 1, 2 and 3 in each of the country considered, with reference to an individual without consort and other sources of income. In Panels a) of these three figures we show the amount of social assistance benefits (broken line) and the total amount of income the individual gets, as a function of the NDC pension matured (all variable are expressed as a fraction of countries' average wage ${ }^{9}$ ). When the ratios between individual NDC pension and average wage is greater than $27 \%$ in Italy, $39 \%$ in Sweden and $15 \%$ (or $21 \%$, see below) in Poland the total income equals the NDC pension since no social assistance benefits are received by the individuals. In the other case, the NDC pension is supplemented by the social assistance integration.

In Panels $b$ ) and $c$ ) we draw some indicators of the incentive problem: Panels $b$ ) show the implicit (marginal) tax rate, defined as the ratio of the increase of total income to the increase of NDC pension: clearly, when individuals' NDC pension (as a ratio of average income) increases, but total benefits increase less, or not at all, because social assistance benefits decrease, the implicit tax rate is positive, whereas equals to zero otherwise. In Panel c) we calculate the Net Present Value Ratio (NPVR) of the NDC pension payments flow, net of the full social assistance benefits

\footnotetext{
${ }^{9}$ We considered the OECD average annual wages in 2009 (latest year available): 27,533 euro for Italy, 36,809 euro for Sweden and 9325 euro for Poland.
} 
payments, setting at 1 the NPVR in absence of social assistance (this choice is justified because, as said, incentives are a key element of our analysis and we are interested in a measure of the difference between the present value of contributions an individual pays and the present value of the flow of benefits she/he will be entitled because of such contributions, not being granted otherwise $)^{10}$.

\subsection{Social assistance minimum pensions in Italy, Sweden and Poland}

\section{Italy}

In Italy there is currently the co-presence of three different public pension calculation rules: people with more than 18 years of work seniority in 1995 have their pension calculated with a traditional DB formula; people that have entered in the labor market since 1996 are subject to a NDC rule; people in between have benefits calculated by a mix of the two systems, in proportion to the working-life spent under each one ${ }^{11}$.

Those who do not fulfill work seniority requirement to be entitled to a DB or mixed pension (20 years of contributions) can claim a pension calculated using the NDC formula, which only requires 5 years of work seniority. However, while pensions computed according the first two systems benefit from a (means-tested) minimum-pension supplement, bringing, as of 2011, the pension to 500-600 euro per month (6500-7800 per year, depending on age), a lower, socialassistance, non-contributory, minimum applies to people whose pension is calculated exclusively through the NDC formula, which in 2011 is worth 430 euro per month (5600 euro per year) and only for those above 70 years of age reaches 600 euro per month. Moreover, in the means-test for the social assistance pension, also the social security pension enters, although with a deduction of $1 / 3$, within the limit of $1 / 3$ of the social assistance pension itself.

Formally, for an individual single:

$$
S A=\max \{0 ; 5592,8-[y-\min (\beta * N D C ; \alpha * 5592,8)]\},
$$

10 Assuming the NPVR is equal to 1 when social assistance benefits do not exist simplifies the calculation of our NPVR, as, by assumption, the current value of the pension contribution flow during an individual's working life is equal to the current value of the NDC pension payments to her/him. In particular, if a proportion $\beta$ of the NDC pension $(N D C)$ can be deducted from the means-test for the social assistance pension (granted to a maximum value of $S A^{\text {max }}$ ), being Cont the contribution paid during a working life of length $L$ and $V$ the life expectancy at retirement, one can write:

$$
N P V R=\frac{\sum_{j=1}^{V}\left(S A_{j}^{\max }+\beta N D C_{j}\right)(1+\delta)^{j}-\sum_{j=1}^{V} S A_{j}^{\max (1+\delta)^{j}}}{\sum_{i=1}^{L} \operatorname{Cont}_{i}(1+\delta)^{L-i+1}}=\frac{\sum_{j=1}^{V} \beta N D C_{j}(1+\delta)^{j}}{\sum_{j=1}^{V} N D C_{j}(1+\delta)^{j}}=\beta
$$

so that the NPVR in this case reduces to the parameter that sets the accumulation rules of NDC and social assistance pensions.

Thus, we arbitrarily assume a NDC pension formula that fully capture the actuarial principle, which is justified because our goal is to show the extent of departure from this principle when one takes into account social assistance. As a matter of fact CAPP_DYN, the microsimulation model we will use below in the analysis (see section 4), calculates the NPVR for each individual and has shown departures from the actuarial principle due to gender and socio-economic differences in mortality (Mazzaferro, Morciano and Savegnago 2011). At the general level, it is often claimed that NDC pensions would not be fair from the actuarial point of view because they would be lower than those private pension funds would pay with the same contributions (Queisser and Whitehouse 2006, Palmer in Holzmann and Palmer 2006). However, such claim derives directly from two specific assumptions: 1) that the return rate in a NDC system, thus the grow rate of total wages, is lower than the risk free, net of managing cost, market interest rate; 2) that annuities are sold in the private market at their true value, which many studies have shown not to be the case (Estelle and Song 2001, Cannon and Tonks 2003, Mackenzie and Schrager 2004, Guazzarotti and Tommasino 2008).

${ }^{11}$ I.e., the number of years of work before and after 1995 over the total. 
where:

$S A=$ social assistance benefits;

$N D C=$ NDC pension;

$y=N D C+$ other sources of income ;

$\alpha=1 / 3=$ maximum deduction from the means-test in terms of social assistance pension;

$\beta=1 / 3=$ proportion of NDC not entering the means-test.

Thus, focusing only on people fully subject to the NDC regime, as shown in Figure 1.a, the social assistance pension offers a minimum income to each individual. People that also benefit from a small NDC pension may reach a total income greater than the minimum by $1 / 3$ of the NDC pension itself. However, for NDC pensions between $20 \%$ and $27 \%$ of average income (between 5600 and 7457 euro per year), total income remains fixed at $27 \%$ of the average income itself. For NDC pensions above such threshold, social assistance benefits fall to 0 and the individual only gets her/his contributory pension. In other words, people without other sources of income will experience an implicit tax rate of $2 / 3$ of their NDC pension at low income levels, which rises to $100 \%$ in the interval $20 \%-27 \%$ of average income (when the limit of $1 / 3$ of the social assistance pension is reached), and falls to zero thereafter (Figure 1.b). The NPVR of the NDC pension flow, computed, as said, net of social assistance benefits (Figure 1.c), drops to 33\% for wages lower than $20 \%$ of average income and then further till a minimum of $25 \%$; above $27 \%$ of the average income the indicator starts rising, going back to the benchmark value of 1 only asymptotically.

\section{Sweden}

The situation in Sweden is not too different than the Italian one. There exists a flat rate social assistance benefit, guarantipension, which is paid to residents independently of previous labor market experience and amounts to 9958 euro per year in 2011, which correspond to 2.13 times a "price-base amount" which is worth 42,800 SEK in 2011. The full amount is paid only to those with at least 40 years of residence in the country, whereas it is correspondently reduced otherwise. The guarantipension is subject to a means-test. In particular, NDC pensions lower than $16 \%$ of average income (5891 euro, 1.26 times the price base) are absorbed by the guarantipension. For those above such limit but with a NDC pension lower than $39 \%$ of average wage (14,352 euro, 3.07 times the price base), total income is given by 6895 euro plus $52 \%$ of the NDC pension. NDC pensions above $39 \%$ of average wage are not entitled to the guarantipension (Figure 2.a) ${ }^{12}$. Figure 2.b shows that the implicit tax rate is equal to 1 till the NDC pension reaches $16 \%$ of average wage (as in this interval everybody are brought up to the same amount of $27 \%$ of average wage), then drops to $48 \%$ till the NDC pension reaches $39 \%$ of average wage, going to 0 thereafter. As for the NPVR (Figure 2.c), the high value of Swedish minimum pension translates in a corresponding lower NPVR for contributors.

\section{Poland}

The situation in Poland is partly different from the other two countries. The Poland system has two minimums, one which is a true social assistance minimum, set at 477 PLN per month in 2011 (about 1435 euro per year, 15\% of average income) and a minimum pension for those who

\footnotetext{
${ }^{12}$ For a couple, amounts and income limits are proportionally lower. Notice that a different benefit (maintenance support for the elderly persons) applies to individuals that do not have enough residence seniority to be entitled to a decent guarantipension. Furthermore, many elderly persons benefit from housing allowances.
} 
contributed for at least 20 (for females) or 25 years (for males) to the social security system. This second minimum, which in the Polish NDC system is also classified as social assistance and financed through general fiscal revenues, is set at 706 PLN per month in 2011 (2123 euro per year, about $23 \%$ of average wage $)^{13}$. Apparently there is no possibility to accumulate either of the two minimums with a NDC pension, so that, as shown in Figure 3.a, there are two flat intervals for total benefits, at $15 \%$ and $23 \%$ of average income (1435 and 2123 euro per year); above such threshold, the individual only gets her/his NDC pension ${ }^{14}$. Implicit tax rates (Figure 3.b) are at 1 till individual's NDC pension becomes greater than the social assistance minimum, then fall and become negative upon reaching the work seniority which allows to benefit from the minimum NDC pension (here assumed to be reached with a NDC pension of $19 \%$ of average income), to finally end up at 0 for NDC pensions above 23\% of average income. The NPVR tends to be 0 when one benefits from one of the minimums (with a hike in between the two), then increases, asymptotically tending to 1 (Figure 3.c).

\footnotetext{
${ }^{13}$ Again, thresholds and amounts are proportionally lower for the couple than for the single, and other sources of social assistance (temporary benefits, housing supplements,...) also exists, being most often administrated at the local level.

${ }^{14}$ In the case of Poland, differently than for Italy and Sweden, we also had to assume a certain number of years of contribution for each NDC pension, as, as said, the minimum social security pension is attributed upon reaching 20 or 25 years of work seniority. The situation shown in Figure 3 is broadly coherent with that of a male working at $50 \%$ of average income for less than 18 years (social assistance minimum), between 18 and 24 years (NDC pension above social assistance minimum but no right to minimum social security pension), between 25 and 30 years (NDC pension brought to the minimum), and above 31 years (individual receives only the NDC pension).
} 


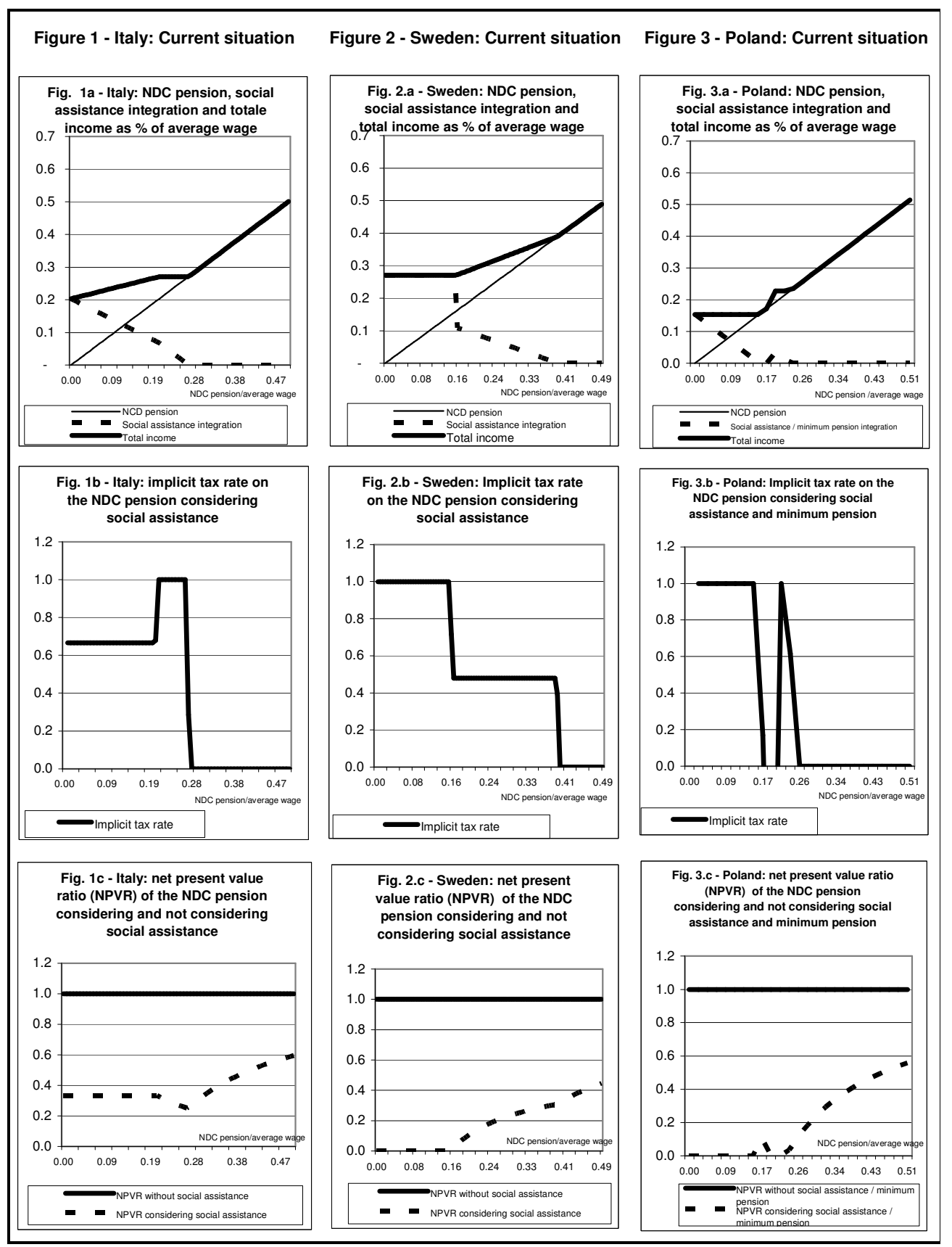

\subsection{An underestimated problem}

As stated previously NDC pension systems fail to deliver actuarial equity and incentive neutrality at low income levels, when social assistance minimums (and the social security minimum, in the case of Poland) are taken into account. This would also originate a regressive feature within the NDC systems, as NPVRs reach the value of 1 only asymptotically as income increases, being significantly lower the lower the pension and the poorer the pensioner.

How important is this issue? Are we dealing with something which is affecting a significant share of workers and pensioners, or just a few, unlucky, individuals?

In Italy, currently 5 millions of pensions, out of 24 millions, benefit from the social security or social assistance minimums (of with 2.2 millions are old-age pensions, 0.8 millions socialassistance pensions and the rest invalidity and survivors pensions, Ministero del lavoro e delle 
politiche sociali 2011). The median pension is around 1000 euro per month (45\% of average income, Istat 2011). Moreover, pension benefits are expected to drop in the future (see below and next section), which implies that data based on current benefit levels could even underestimate the problem.

The problem in Poland, as seen in Figure 3, seems less pronounced, but this is mostly due to the lower levels of the two minimums (even when considered as a $\%$ of average wage) compared with the other two countries. As a matter of fact, it is expected that minimums will play an increasing role in the future and a change is expected "of the role of minimum pension from one of the tools supporting redistributive policy to the main tool of social policy preventing poverty among elderly persons" (Chlon-Dominczak and Strzelecki 2010); indeed, while Poland experienced during the last decade sustained employment and wage growth, its pension system will have to cope with a labor market where people are not anymore invariably registered as formally employed, as it was in the old era.

Finally, the strength itself of Sweden, which is able to grant to residents a high living standard, with a social assistance minimum standing just below 10,000 euro per year, triggers the weakness of the incentive structure of its NDC system, which does not perform well in terms of implicit tax rate and NPVR.

As a further element to evaluate the relevance of the issue we are dealing with, Table 1 shows the number of contribution years a worker at different levels of income (from 50\% to $150 \%$ of the average) would need to reach a NDC pension equal to the social-assistance minimum (Italy and Sweden) and to the two distinct social assistance and social security minimums existing in Poland. Calculations are rough, but give powerful hints. Based on official theoretical replacement rates in 2006, in Italy an average worker has to contribute for 10 years to mature a NDC pension just equal to the social assistance pension, which rise to 20 years for a worker at $50 \%$ of average income. In Poland an average worker needs 11 and 16 years to reach the two minimums respectively, which become 21.5 and 32 years for workers paid 50\% of the average. The Swedish situation, as seen above, appears worse than the others, because the social assistance pension is proportionally higher: an average worker will need more than 20 years of contribution just to mature a pension equal to the guarantipension, while a worker at $50 \%$ of the average income will probably not reach such minimum with the contributions of her/his entire career. Performing similar calculations using the replacement rates expected in 2046, as also shown in Table 1 (which would be more correct, as we are dealing with pensions in the reformed NDC systems), would only make things worse, even when the private pension component is taken into account.

Given this evidence, the possibility that low earners could end up with a NDC pension lower, or not much greater, than social assistance minimums appears as a realistic one and some individuals could actually be better-off hiding in the shadow economy than surfacing, which challenges the standard assumption that NDC pensions replicate private savings. Indeed, while this may be a problem of minor importance in countries where the informal economy only plays a marginal role, as in the case of Sweden, this is certainly not the case in Italy, as well as in many developing countries that could adopt the NDC system. From this point of view NDC systems could perform even worse than traditional DB systems, as these last rewarded length of contributions and were generally more generous, so that workers had some incentive at least to pay enough contribution to get recognition for each year of work and a concrete perspective of getting a pension significantly higher than social assistance minimums. 


\begin{tabular}{l}
\hline \multicolumn{2}{|c|}{ Table 1 - Number of years of contribution needed to mature a NDC pension equal to social assistance benefits (in Italy and Sweden) and } \\
to social security minimum pension (in Poland)
\end{tabular}

\section{A microsimulation analysis}

To examine the extent of the problem described above, we use a dynamic microsimulation model (CAPP_DYN) of the Italian population and pension system, which follows people through their life and work, retirement and death. Dynamic microsimulation allows not only to discuss average levels, but also the distributive properties the pension system is going to show in the future decades, while following people on a very wide variety of work and life events. Furthermore, using microsimulation, it is possible to better assess issues like pension adequacy, incentive neutrality and "fairness" (at the inter-generational, intra-generational and gender levels), which are closely related to the issue we are dealing with in this paper.

Below, we firstly briefly describe the main features of CAPP_DYN and then we show results related to the issue of the likely relevance of social assistance allowances in the Italian NDC system. In section 5 we use the model to evaluate the effects of increasing the possibility to accumulate social assistance and NDC pensions.

\subsection{The CAPP_DYN microsimulation model}

The results discussed in this paper are obtained using the latest version of CAPP_DYN (Mazzaferro and Morciano 2011), a population-based dynamic microsimulation model firstly built by the Center for the Analysis of Public Policies (CAPP) in 2004 for the Ministry of labor and social affairs and further developed and updated ever since ${ }^{15}$. It is specifically designed to analyse the long-term economic well-being of a relatively large and representative sample of the Italian population $^{16}$, over the period 2010-2050. The model takes the initial population from the 2007 wave of the IT-SILC, the Italian version of the European Union Statistics on Income and Living Conditions survey, and projects individuals forward through time (Figure 4).

All individuals in the sample are involved in a considerable number of demographic and socio-economic events, such as birth, education, (re)marriage and divorce, work, retirement, disability and death, dealt with in different modules, as described in Figure $5^{17}$. Events are modelled by means of finite and discrete Markovian processes and using the Monte Carlo technique. Thus, to

\footnotetext{
${ }^{15}$ In 2009 CAPP_DYN has been rewarded by the EU through the Progress program financing "actions related to the development of administrative datasets and models for labor market and pension analysis".

${ }^{16}$ Currently, the base year population consists of about 270,000 sample members.

${ }^{17}$ While the unit of simulation is the individual, CAPP_DYN also keeps information on family structure and any changes this may be subjected to over the course of time.
} 
model a change in the socio-economic characteristics of a sample member from one year to the next, one first fits to the data statistical models that capture all relevant aspects of the individual's transitions; then, one simulates the change in the individual's status, by making random drawings from the estimated models.

Transition probabilities of the socio-economic circumstances depend on individual characteristics and are estimated using a wide set of data sources. Certain behavioral functions have been introduced, the main one being that governing retirement choices. The model is calibrated in order to follow official GDP and wage trends.

Each annual cycle starts running a set of demographic modules (mortality, fertility, net migration) which, in line with the demographic projections of the Italian National Statistics Institute (ISTAT), determines the size and structure of the population in each year of the simulation horizon. Household formation/dissolution modules (parental house living decision, (re)marriage and divorce) allow the definition of the family structure in which each sample member is allocated ${ }^{18}$.

The second set of modules allows the simulation of individuals' educational choices, job decisions and earnings. In each of the simulated year, individuals incur in the probability of changing occupational status (full-time, part-time, out of the labor market, unemployed). For employed people, gender and sector-specific earning equations are used to compute cross-sectional age-earning profiles, making some assumptions regarding the treatment of the unobservable individual effect and expected earnings growth rate over the simulated period.

Once the population structure has been defined, and labor incomes have been generated, the model simulates the main social security benefits in considerable institutional detail, according to the pension scheme provisions in force. Individuals' retirement choice and the computation of oldage, seniority and survivors pension benefits, as well as of social allowances, social assistance increases (maggiorazioni sociali) and social security supplements (integrazioni al minimo) are simulated in this module.

Consequently, the model can estimate the distributional effects of key social security components, as well as the impact of social security reforms, allowing for the implementation of both cross-sectional (at different point of time) and inter-temporal life-cycle (of individuals living during different periods) analyses. The effect of policy changes and other circumstances can be analyzed comparing two or more projections.

\footnotetext{
${ }^{18}$ Health status and disabilities profiles are simulated using a procedure described elsewhere (Baldini, Mazzaferro and Morciano 2008, Mazzaferro and Morciano 2011). Health status is not a direct outcome, but indirectly affects other economic dimensions (i.e. labor market position, earnings and receipt of disability benefits).
} 


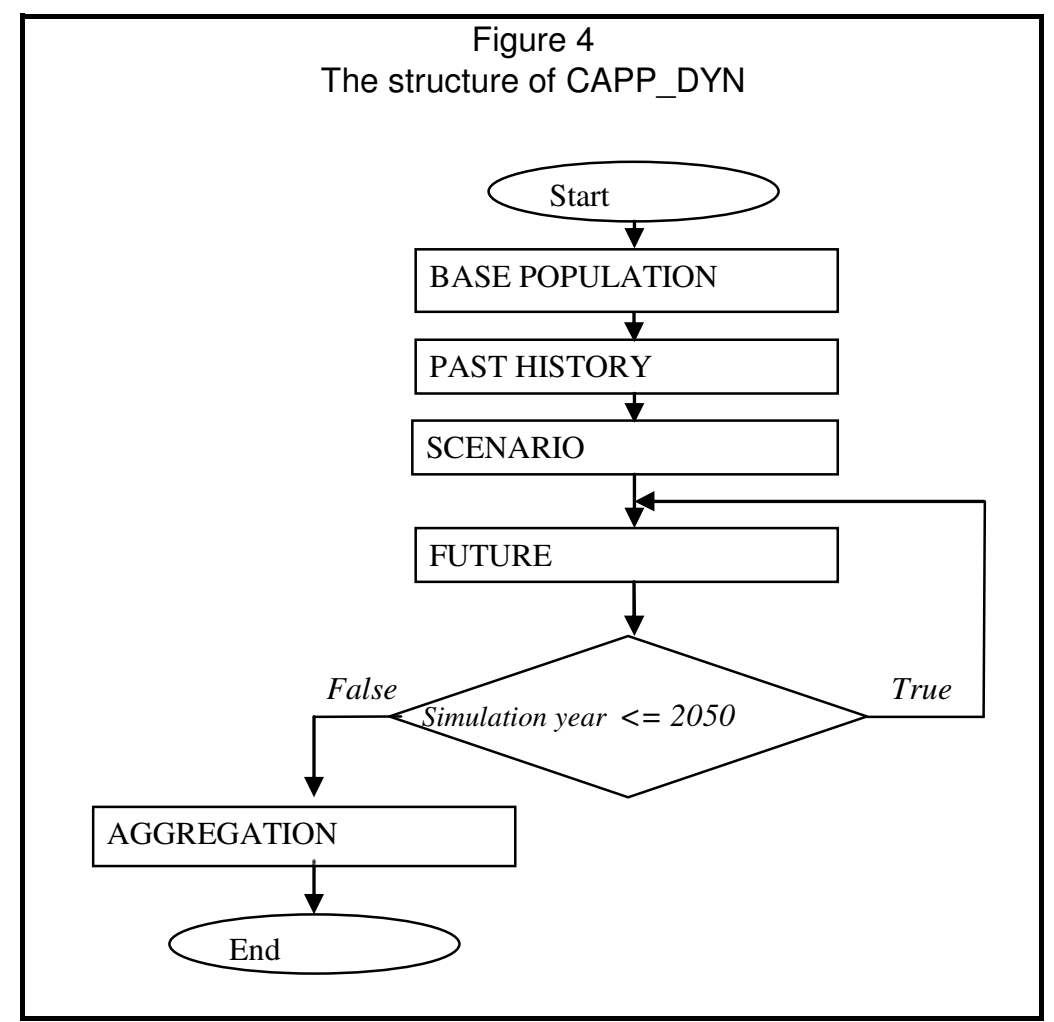

Figure 5

The modules of CAPP_DYN

\begin{tabular}{|c|c|}
\hline \multirow{7}{*}{$\begin{array}{l}\text { Demography } \\
\text {-Mortality } \\
\text {-Fertility } \\
\text {-Net Migration } \\
\text {-Children leaving home } \\
\text {-(re)Marriage } \\
\text {-Separation }\end{array}$} & \\
\hline & \multirow{6}{*}{$\begin{array}{l}\text { Education and labour } \\
\text {-Education (three levels) } \\
\text {-Transition to the labour market } \\
\text {-Occupational status (employed/unemployed/not involved } \\
\text { in the labour market) } \\
\text {-Type of employment (employee/ self-employed) } \\
\text {-Income generation (earnings) }\end{array}$} \\
\hline & \\
\hline & \\
\hline & \\
\hline & \\
\hline & \\
\hline \multicolumn{2}{|l|}{$\begin{array}{l}\text { Modelling Population } \\
\text { at time } \mathrm{t}\end{array}$} \\
\hline 4 & $\downarrow$ \\
\hline $\begin{array}{l}\text { Next year } \\
(t=t+1)\end{array}$ & \multirow{4}{*}{$\begin{array}{l}\text { Social Security } \\
\text {-Retirement decision } \\
\text {-Old Age Pension } \\
\text {-Survival pension } \\
\text {-Disability pension } \\
\text {-Social Assistance Pension }\end{array}$} \\
\hline $\boldsymbol{T}$ & \\
\hline Modelling Population & \\
\hline at time $(\mathrm{t}+1)$ & \\
\hline
\end{tabular}




\subsection{Results of the simulation}

In the coming decades, Italian society and its economy are expected to experience important structural changes, in line with trends already taking place (Mazzaferro and Morciano, 2011). For the purpose of the present study we present some indicators of the adequacy of the reformed pension system first, and we then move to analyze the part of the population of pensioners directly interested by the coexistence of NDC pensions and social allowance benefits. We specifically attempt to address the questions raised in subsection 3.3, namely quantifying the relevance of the problem there discussed and provide information on the socio-economic characteristics of those who are likely to receive social allowance benefits as supplement to their own pension income.

Figure 6 shows the evolution of the replacement rate of new retirees (computed as the mean between individuals' ratio of accrued pension in the first year of retirement and their last earning, both gross of income taxes and social security contributions). The figure highlights a significant reduction of the indicator, especially in the second part of the period, when the NDC system will be completely phased-in. The average replacement rate, slightly above $70 \%$ at the beginning of the estimated period, decreases to about $50-55 \%$ at the end of it. It seems possible to identify three different time-intervals which witness the phasing-in of the NDC system. From 2010 to 2025 we project a slow reduction in the average replacement ratios of new pensioners, as many workers will still retire with the old, DB, formula. The reduction is faster from 2025 to 2035, when all workers will retire with a large and increasing part of their pension calculated through the NDC formula, with those who the full NDC system applies not benefiting anymore from the social security minimum pension (integrazione al minimo), but only from the social assistance minimum. Afterwards average replacement ratios are constant at around 50-55\%, as all new pensioners are of the NDC type.

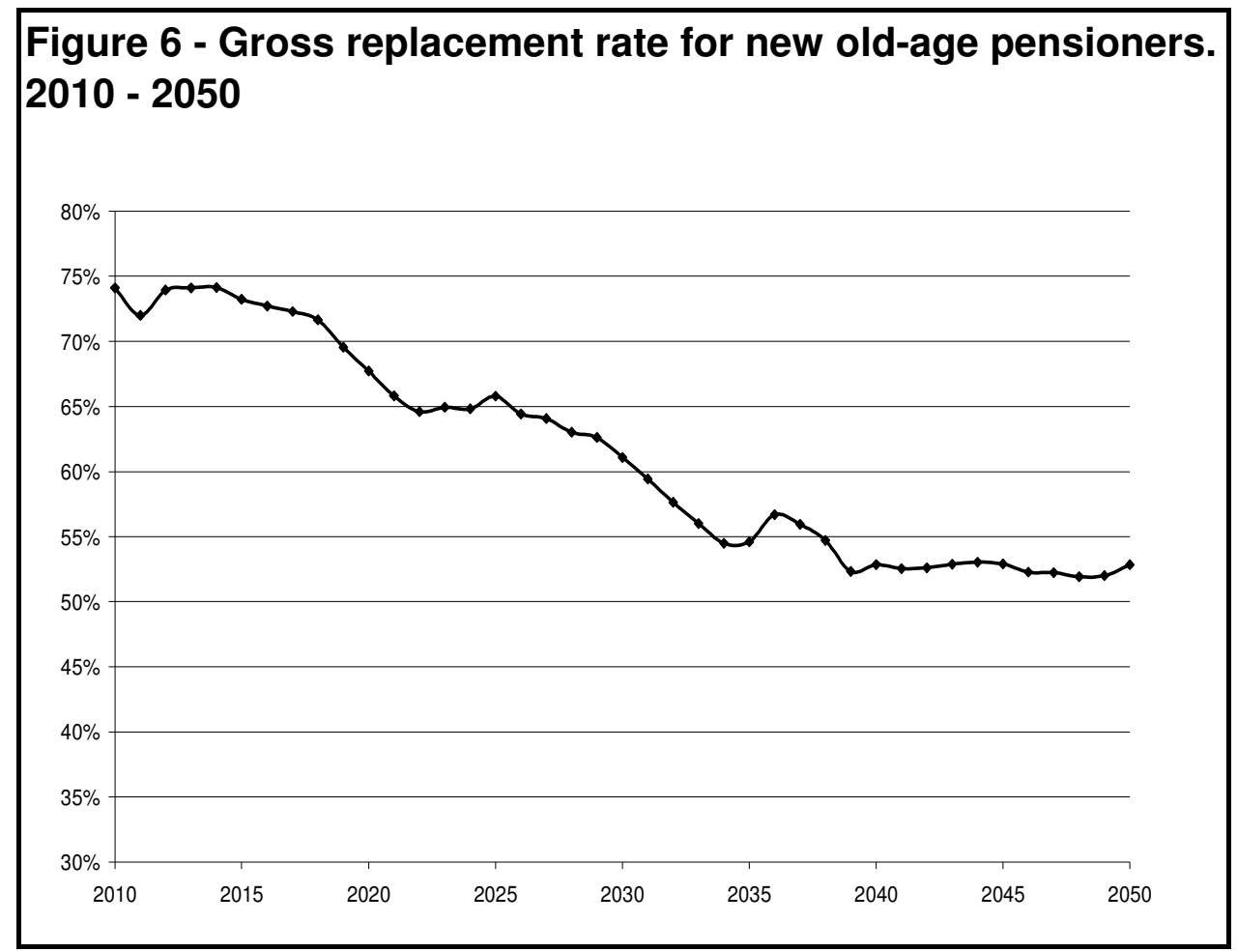


Figure 7 shows the evolution of the ratio between average old-age pension and average earning over the period under observation, computed among the entire population of pensioners and workers, respectively. In the same figure we also report the share of old-age pensions under the $60 \%$ of the median earning. The first indicator can be considered as a proxy of the condition of pensioners with respect to workers. According to our simulation it remains nearly constant in the first two decades, until 2030; afterwards, it decreases continuously, till the end of the simulation. Two factors are jointly at work in explaining this evolution; on the one hand, the absence of an indexation of pension benefits to real earnings tends to reduce the relative value of the former; on the other hand, the slow transition towards the less generous NDC system and the increase of statutory retirement age produce a more ambiguous effect, which helps to explain both the initial rise and the reduction of the ratio in the second part of the period under observation. The second indicator in the graph shows that in the first part of the simulation the share of old-age pensions below $60 \%$ of the median earning is expected to decrease, while the phasing-in of the NDC system which will take place after 2030 will reverse the trend, a dynamic which mirrors these of the ratio between average pension and average earning. Overall, Figure 7 draws a scenario where the average risk of poverty for the older part of the population is likely to rise in the distant future, exacerbated by the fact that individuals are expected to live much longer than now.
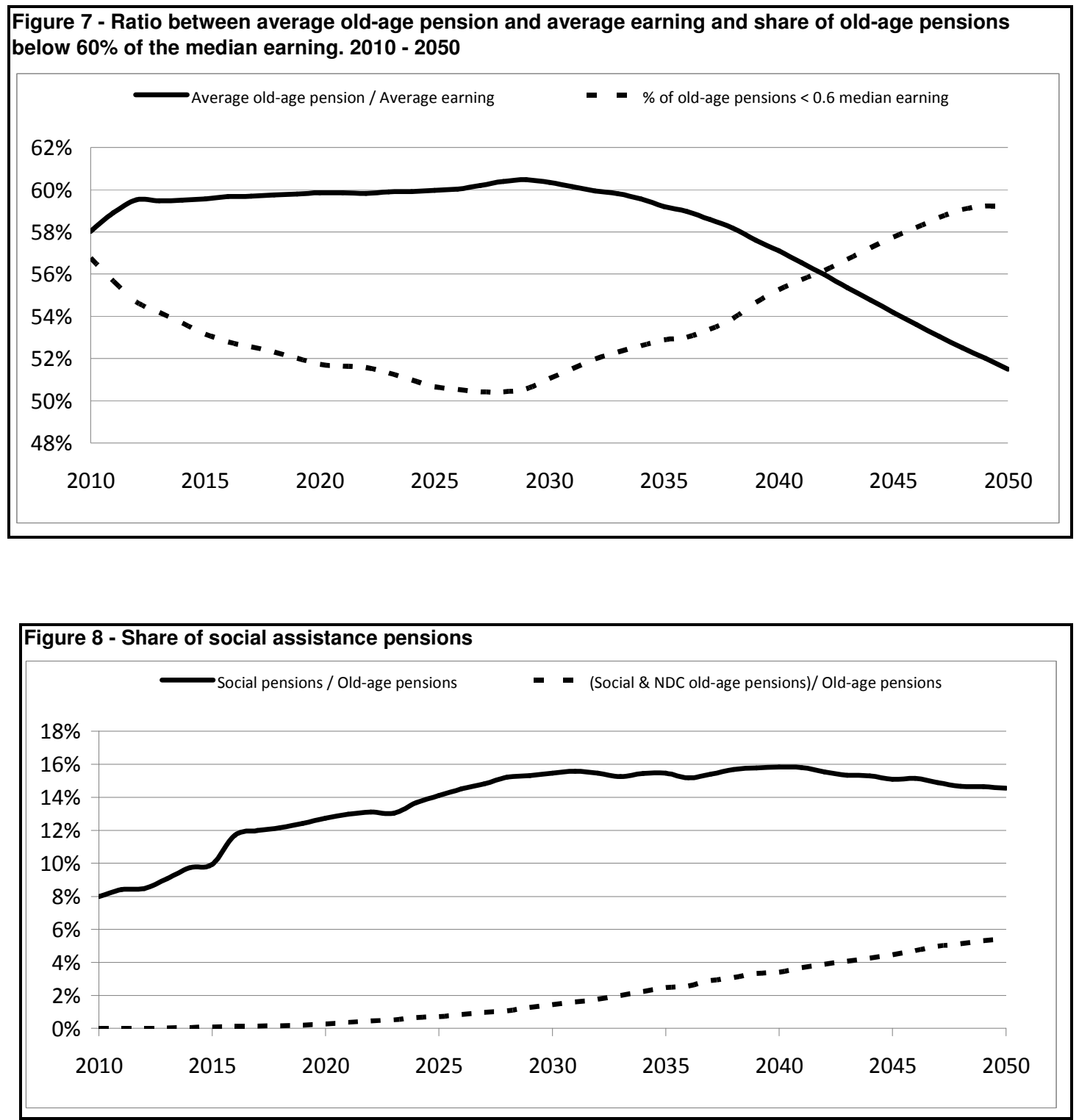
Figure 8 gives a broad description of the weight of social assistance pensions in the Italian social security system for the next decades. As a percentage of old-age pensions they are slightly above $8 \%$ in 2010 , but over the considered period, the share is expected to continually grow up to nearly $16 \%$ in 2030 . Afterwards the share of social allowance pensions over old-age pensions will remain around this level till the end of the simulation. The proportion of individuals receiving both a social assistance pension and a NDC pension will grow continuously, from nil at the beginning of the simulation to nearly $6 \%$ of the whole old-age pensioners at the end of it.

Table 2 compares some demographic and economic information of the population under observation with the remaining part of NDC old-age pensioners. As for the gender composition it is immediately clear that women are overrepresented among those NDC pensioners who receive a social pension. With respect to the civil status there are less married individuals, a similar share of singles and more divorced and widows. Seniority at retirement appears sensibly lower (23.9 years versus 35.1 years) and consequently a larger share of individuals score less than 30 years of contributions. Having shorter carriers the group under observation reaches a considerably lower replacement rate between old-age pension and last year wage (35\% versus 55\%) even if retirement age is higher (67.4 years versus 66.2 years). Finally, it is noticeable the higher share of the selfemployed among those who will receive both a NDC pension and a social assistance pension.

Interestingly (but not shown in this table) only $40 \%$ of the population that receives a social assistance pension together with an NDC pension becomes eligible in the first year of retirement, the remaining part being those who will pass the means-test in subsequent years, given a worsening in the economic conditions caused by changes in the family composition and/or by the progressive devaluation of the NDC benefits (constant in real terms) in face of a threshold that grows in line with real GDP.

With respect to the adequacy problem the current legislation does not seem to be able to cope with the problem, at least entirely. We computed the average value of social assistance pension and the average value of the sum of social assistance and old-age pensions. Table 3 displays the ratio between these two values and the mean old-age pension or the mean earning in different years of the simulation starting from 2020. Starting from the left side of the table results describes a situation where the average value of social pension will at best remain constant with respect to average old-age pension and will decrease with respect to average earning, but starting from a relative low level. A slightly less pessimistic message comes from figures in the right side of the table where the sum of old-age and social pensions is compared with old-age pensions and earnings. In this case both ratios are increasing although this may be due to both the NDC system reaching maturity (and thus liquidating benefits associated with longer seniority) and being less generous (with an higher share of population receiving, as seen, a social assistance add-up). 


\begin{tabular}{|c|c|c|c|c|c|c|c|}
\hline & $\begin{array}{r}\text { NDC old-a } \\
\text { not rece } \\
\text { pe }\end{array}$ & $\begin{array}{l}\text { ioners } \\
\text { cial }\end{array}$ & $\begin{array}{l}\text { NDC olc } \\
\text { receivin }\end{array}$ & $\begin{array}{l}\text { ssioners } \\
\text { ensions }\end{array}$ & Test o & n the diffe & rence \\
\hline & mean & $s d$ & mean & $s d$ & & & \\
\hline Female & 0.39 & 0.49 & 0.74 & 0.44 & female & $-0.297 * * *$ & $(-72.21)$ \\
\hline Couples & 0.46 & 0.5 & 0.23 & 0.42 & _st1 & $0.183^{* * *}$ & -37.74 \\
\hline Single & 0.21 & 0.41 & 0.22 & 0.41 & st2 & $-0.0330^{* * *}$ & $(-8.44)$ \\
\hline Divorced & 0.09 & 0.28 & 0.2 & 0.4 & st3 & $-0.0894 * * *$ & $(-25.44)$ \\
\hline Widow & 0.24 & 0.43 & 0.34 & 0.48 & _st4 & $-0.0605 * * *$ & $(-13.84)$ \\
\hline Seniority at retirement & 35.14 & 7.28 & 23.94 & 8.83 & acontrib & $9.926 * * *$ & -110.16 \\
\hline Less than 10 years & 0.01 & 0.12 & 0.09 & 0.28 & acontr10 & $-0.104 * * *$ & $(-29.89)$ \\
\hline Between 11 and $20 \mathrm{yrs}$ & 0.04 & 0.19 & 0.27 & 0.45 & acontr20 & $-0.249 * * *$ & $(-54.29)$ \\
\hline Between 21 and $30 \mathrm{yrs}$ & 0.15 & 0.36 & 0.39 & 0.49 & acontr30 & $-0.0746^{* * * *}$ & $(-16.44)$ \\
\hline More than $30 \mathrm{yrs}$ & 0.8 & 0.4 & 0.25 & 0.44 & $\begin{array}{l}\text { acontr30p } \\
\text { lus }\end{array}$ & $0.428 * * *$ & -111.84 \\
\hline Previously priv. dep & 0.77 & 0.42 & 0.63 & 0.48 & _setpen 1 & $0.0575^{* * * *}$ & -12.13 \\
\hline Previously pub. Dep. & 0.15 & 0.36 & 0.06 & 0.24 & setpen2 & $0.104 * * *$ & -35.69 \\
\hline Previously self empl. & 0.09 & 0.28 & 0.3 & 0.46 & _setpen3 & $-0.162 * * *$ & $(-38.03)$ \\
\hline Replacement rate & 0.55 & 0.13 & 0.35 & 0.15 & ts_ass & $0.198^{* * *}$ & -25.95 \\
\hline & & & & & _ts_ass & $0.200^{* * *}$ & -94.73 \\
\hline Retirement age & 66.2 & 1.82 & 67.43 & 0.75 & eta & $-2.374 * * *$ & $(-41.29)$ \\
\hline & & & & & _etapen & $-0.714 * * *$ & $(-78.82)$ \\
\hline & & & & & grage1 & $0.154^{* * *}$ & -33.27 \\
\hline & & & & & grage2 & $-0.0765 * * *$ & $(-15.38)$ \\
\hline & & & & & grage3 & $-0.0775^{* * *}$ & $(-21.88)$ \\
\hline Observations & 4336 & & 423 & & $\begin{array}{l}N \\
t \text { statistics in } \\
{ }^{*} p<0.05,{ }^{* *}\end{array}$ & $\begin{array}{c}58238 \\
\text { parentheses } \\
p<0.01,\end{array}$ & $p<0.001$ \\
\hline
\end{tabular}

\begin{tabular}{|c|c|c|c|c|}
\hline \multicolumn{5}{|c|}{ Table 3 - Adequacy for old-age pensioners who receive a social assistance benefit } \\
\hline \multirow[t]{2}{*}{ Year } & \multirow{2}{*}{\multicolumn{2}{|c|}{$\begin{array}{l}\text { Average social pension as a percentage of: } \\
\text { average old-age pension } \quad \text { average earning }\end{array}$}} & \multicolumn{2}{|c|}{$\begin{array}{c}\text { Average level of (social pension + old age } \\
\text { pension) as a percentage of: }\end{array}$} \\
\hline & & & average old-age pension & average earning \\
\hline 2020 & $17.40 \%$ & $10.40 \%$ & $37.40 \%$ & $22.40 \%$ \\
\hline 2030 & $17.30 \%$ & $10.40 \%$ & $37.10 \%$ & $22.30 \%$ \\
\hline 2040 & $17.90 \%$ & $10.10 \%$ & $40.90 \%$ & $23.10 \%$ \\
\hline 2050 & $18.50 \%$ & $9.40 \%$ & $47.10 \%$ & $24.00 \%$ \\
\hline
\end{tabular}

Moving now to the incentive component of the story the next two graphs check whether the CAPP_DYN model is able to capture the incentive structure that we computed for the representative individual in subsection 3.1. Therefore we computed, only on those individuals that are not married, both the implicit tax rate and the NPVR, both shown, as in Figure 1, as a function of the NDC pension in percentage of average earning. While, for computational reason, the implicit tax rate is computed on individuals who are single, receive a NDC pension and a social pension in certain year (2050 in the graph), observations reported for the NPVR are taken on the whole panel of (not married) NDC pensioners. It is immediate to notice that the left part of the graph reproduces exactly the dynamic of Figure $1 . b^{19}$. As for the right panel of the graph (which shows NPVRs on a interval larger than in Figure 1), NPVRs of observed pensioners increase as the level of old-age

\footnotetext{
${ }^{19}$ More precisely, it reproduces the first two segments shown in Figure 1.b.
} 
pension grows, as in Figure 1.c. It is however important to note that simulated NPVRs show a certain variety, due to individuals' history, and would not be equal to one even if social assistance would be excluded from the simulation, as, in particular, both the gender composition and the year of birth affect the calculation.

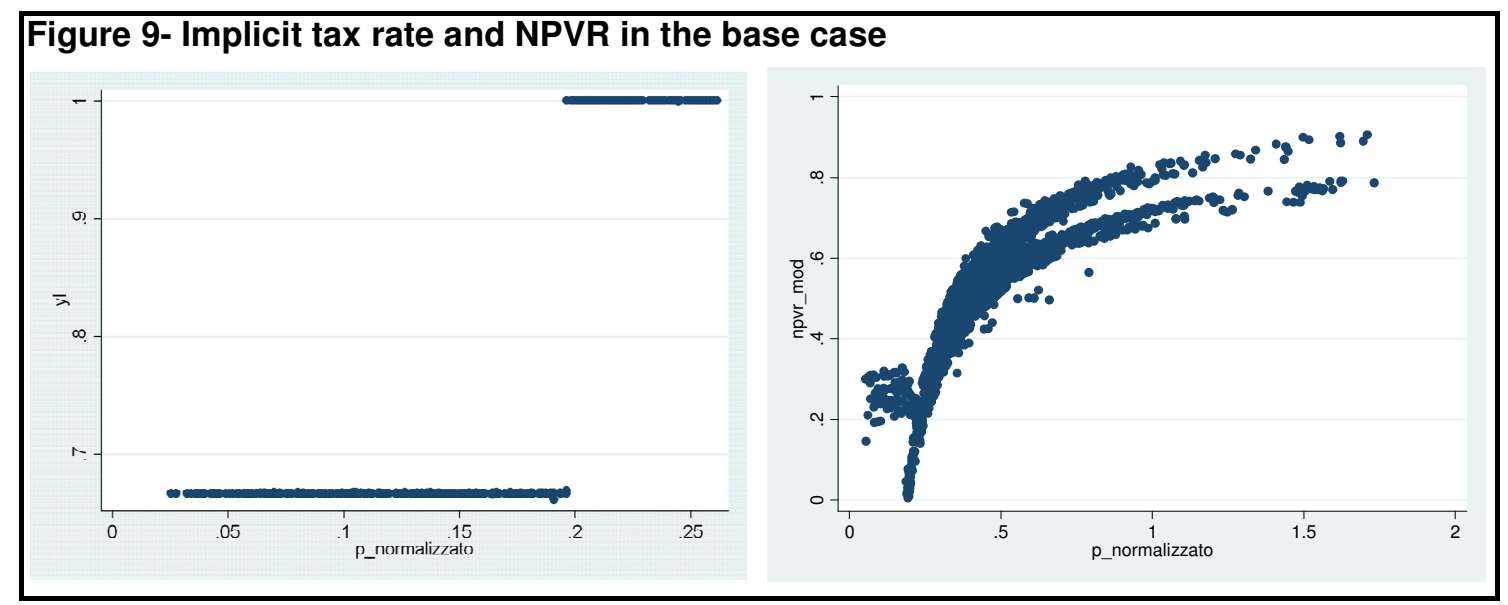

\section{Increasing accumulability of social assistance and NDC pensions}

\subsection{A parametric reform}

In the scenario described above, we envisage to intervene with a simple parametric reform, increasing the possibility to cumulate social assistance and NDC pension. As said before, currently in Italy only a proportion $\beta=1 / 3$ of the NDC pension does not enter in the means-test for claiming the social assistance pension, within a further limit $\alpha=1 / 3$ of the social assistance pension itself. While $\alpha$ is responsible for the implicit tax rate reaching 1 in Figure 1.b, it can easily be dropped from the analysis, working only on $\beta$, the extent of the deduction of the NDC pension from the means-test. Accordingly, we assume a policy scenario where $\beta$ rises to $1 / 2$ and the $\alpha$ limit is lifted ${ }^{20}$.

Clearly, while dropping $\alpha$ allows to avoid the implicit tax rate reaching 1 , the parametric intervention on $\beta$ does not eliminate completely the incentive problem, only making it less pronounced in the interval where social assistance benefits are positive. Moreover, while such intervention certainly costs to the public purse, maintaining in place the means-test requirement to benefit from social assistance allows us to confine the improvement of the incentive structure and of pension adequacy only to those that were actually hit in their incentives and do not have other sources of income apart from their pension. Besides, the selective nature of this program allows to containing its cost.

\footnotetext{
${ }^{20}$ For any given $\beta$, results are unaffected for each $\alpha \geq \beta /(1-\beta)$. Thus, in the status quo with $\beta=1 / 3$, the limit of "within $\alpha$ of the social assistance pension" would be redundant for $\alpha \geq 1 / 2$. In the policy scenario where $\beta$ rises to $1 / 2$, dropping $\alpha$ from the analysis is equivalent to assume it is brought to any value $\geq 1$.
} 
The new situation is described in Figure 10, which is also shown aside with Figure 1 (the status quo) and Figure 11 (which will be discussed in Section 5.2 below) for comparison ${ }^{21}$. In the reformed scenario, an individual benefits from a social assistance add-up to her/his NDC pension till the latter reaches 11,400 euro, instead of the previous 7600, and till such threshold the implicit tax rate drops to $50 \%$, instead of the previous 66\%-100\% (Panels $a$ and $b$ ). The NPVR in the interval where social assistance benefits are positive is still lower than 1 , but not as much as before (it drops to just 0.5 , instead of 0.33 ).

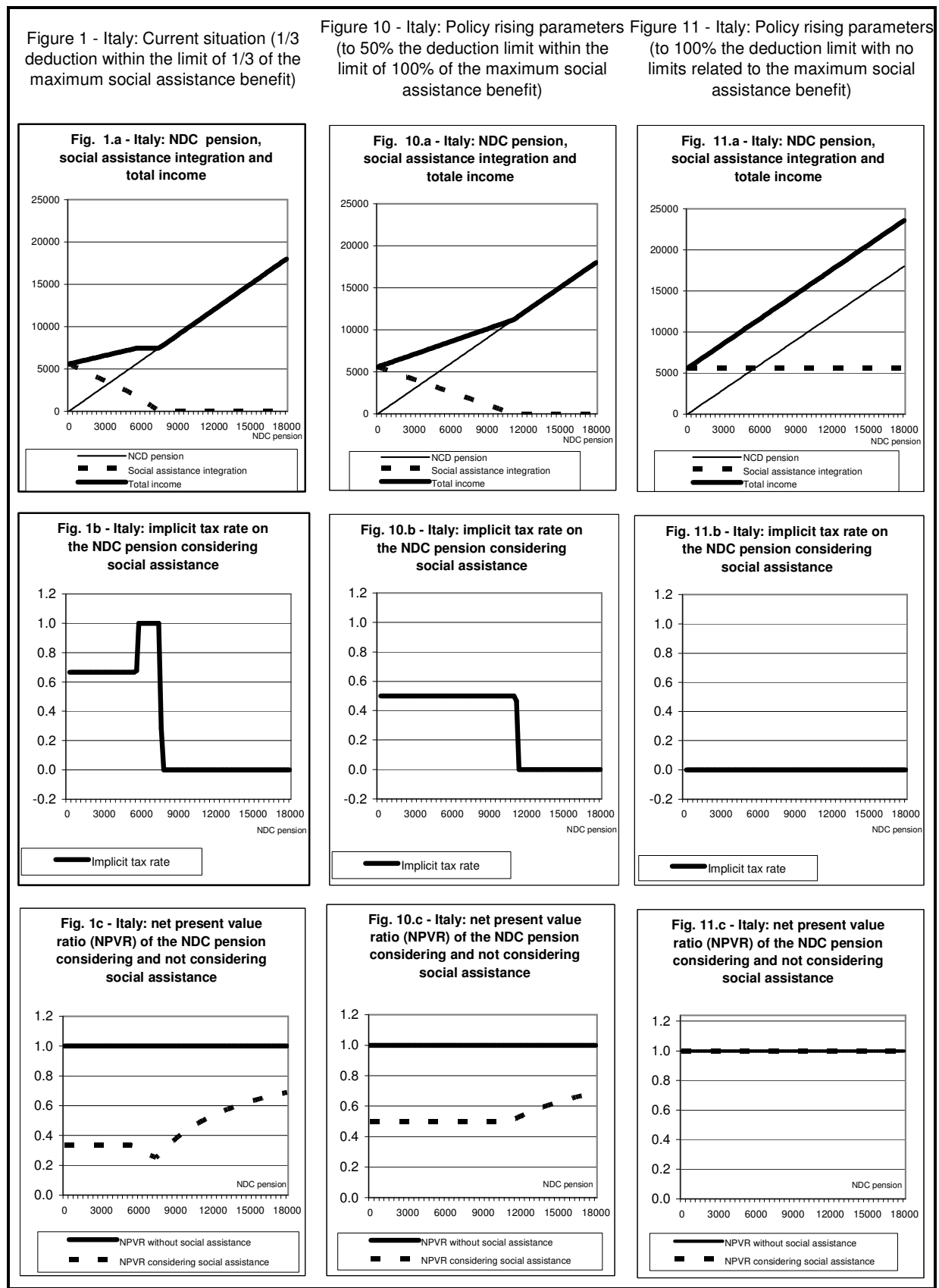

\footnotetext{
${ }^{21}$ NDC pension, social assistance benefits and total income are now expressed in euro (at 2011 value) instead than as ratios to average earnings.
} 
With these more theoretical results in mind, we ran the microsimulation model. Figure 12-15 and Table 4 show the results of CAPP_DYN in the same assumption as in Figure $10(\beta=1 / 2$ and $\alpha$ dropped from the analysis) and in an alternative specification where $\beta$ further rises to $2 / 3$ (again with $\alpha$ dropped). Figures 12 and 13, focus on our two efficiency indices, the implicit tax rate and the NPVR, shown in Figure 9 above for the base case. Table 4 deals with adequacy, mimicking the previous Table 3, in our two simulation scenarios. Figure 14 compares the number of social assistance beneficiaries among old-age pensioners; Figure 15 shows an estimation of the associated macroeconomic costs.

Figure 12 shows how easing the rules on accumulation of social assistance and NDC pension dramatically reduces the implicit tax rates (as expected, from $66.6 \%$ in the base case, to $50 \%$ and to $33.3 \%$ respectively in the two alternative scenarios). Furthermore, the interval where Figure 9 shows and implicit tax rate equal to 1 disappears, due to the dropping of $\alpha$. However, one has to notice that, due to the increasing interval where social assistance benefits are positive, the implicit tax rate remains positive for the entire interval considered in the $x$-axis.

As for NPVRs, Figure 13 again shows an improvement with respect to the base case depicted above in Figures 1.c and in the right panel of Figure 9. What matters now is that the NPVR values increase in the area on the left side of the curve (i.e. for values of the pension to average earning ratio, on the $x$-axis, lover than 0.4 ) from $1 / 3$ in the base case to $1 / 2$ and $2 / 3$ in the two alternative scenarios respectively.
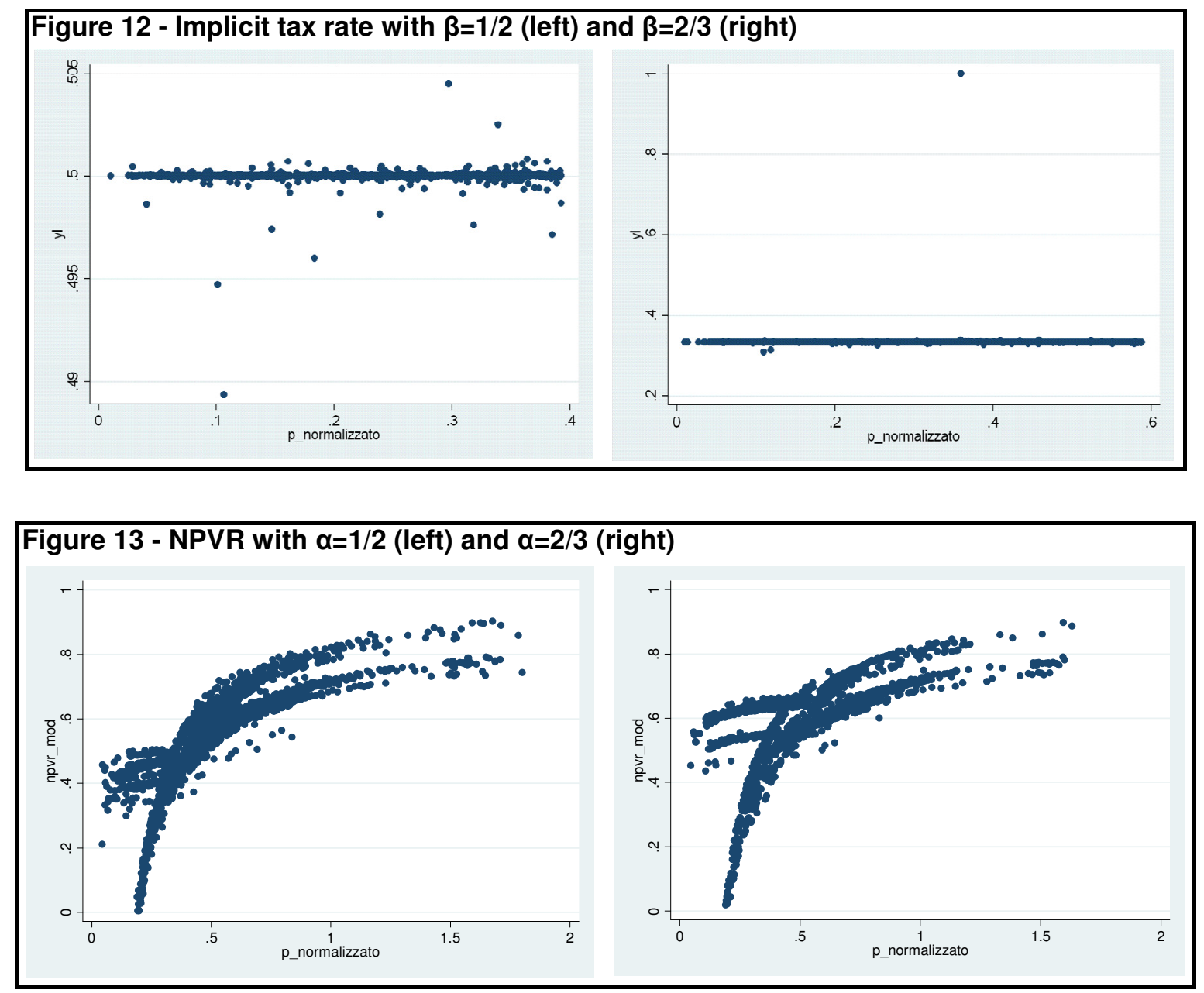
Having shown that the two efficiency indicators actually improve in the two alternative scenarios simulated, Table 4 deals with adequacy. While the value of the average social pension does not change significantly, with respect to the baseline, both as a ratio of the mean old-age pension and of mean earnings, what matters now is that a much larger number of NDC pensioners benefit for a social assistance add-up, so that there is a substantial increase of total benefits (NDC pension + social assistance): the average level in 2050 rises from $47.1 \%$ of average old-age pension in the baseline (see Table 3 above) to $60.2 \%$ and $78.5 \%$ respectively in the two simulations; as percentage of total earning it rises from $24 \%$ to $30,4 \%$ and $39.7 \%$ respectively.

As for the number of beneficiaries of social assistance supplements, Figure 14 compares the number of old age pensioners who receive social allowance under the status quo situation and under our proposal. We scaled the numbers of our estimation in order to make inference to the whole Italian population. The figure shows that, as the NDC system starts being phased in, the difference in absolute terms between the two alternatives keeps growing, reaching roughly 1 million at the end of the simulation period in the case of $\beta=1 / 2$. In case $\beta$ further rises to $2 / 3$ also the number of recipients among old-age pensioners rises, till 2.3 millions.

All these nice features, however, come with a cost. Increasing the number of pensioners receiving social assistance benefits clearly increases expenditure. Figure 15 compares the expenditure for social assistance benefits in the baseline and the two alternative scenarios. The expenditure rises from $1.2 \%$ of the total wage mass (here expressed as the sum of dependent and self employed labor gross incomes) to $2 \%$ and $3.3 \%$ when $\beta$ rises to $1 / 2$ and $2 / 3$. Indeed, while the expenditure increase is concentrated on a period where the current pension expenditure forecasts shown a sharp drop (Department of General Accounts 2011), and thus an increase of expenditure could be borne by the public budget, it should be noticed that the more $\beta$ rises, the more the social assistance pension tends to become a universalistic (although means-tested) zero-pillar benefit, which would require, as argued in the next subsection, a rethinking of the overall pension system organization.

\begin{tabular}{|c|c|c|c|c|}
\hline \multicolumn{5}{|c|}{$\begin{array}{l}\text { Table } 4 \text { - Adequacy for old-age pensioners who receive a social assistance benefit in the } \\
\text { simulation scenarios }\end{array}$} \\
\hline \multicolumn{5}{|c|}{ A) $\beta=1 / 2$ (50\% accumulability of NDC pension and social assistance pension) } \\
\hline \multirow[t]{2}{*}{ Year } & \multirow{2}{*}{\multicolumn{2}{|c|}{$\begin{array}{l}\text { Average social pension as a percentage of: } \\
\text { average old-age pension } \quad \text { average earning }\end{array}$}} & \multicolumn{2}{|c|}{$\begin{array}{l}\text { Average level of (social pension }+ \text { old age } \\
\text { pension) as a percentage of: }\end{array}$} \\
\hline & & & average old-age pension & average earning \\
\hline 2020 & $18.98 \%$ & $11.32 \%$ & $42.39 \%$ & $25.29 \%$ \\
\hline 2030 & $17.72 \%$ & $10.63 \%$ & $44.05 \%$ & $26.43 \%$ \\
\hline 2040 & $17.57 \%$ & $9.88 \%$ & $50.53 \%$ & $28.42 \%$ \\
\hline 2050 & $17.21 \%$ & $8.69 \%$ & $60.22 \%$ & $30.40 \%$ \\
\hline \multicolumn{5}{|c|}{ B) $\beta=2 / 3$ (66,6\% accumulability of NDC pension and social assistance pension) } \\
\hline \multirow[t]{2}{*}{ Year } & \multirow{2}{*}{\multicolumn{2}{|c|}{$\begin{array}{l}\text { Average social pension as a percentage of: } \\
\text { average old-age pension } \quad \text { average earning }\end{array}$}} & \multicolumn{2}{|c|}{$\begin{array}{c}\text { Average level of (social pension + old age } \\
\text { pension) as a percentage of: }\end{array}$} \\
\hline & & & average old-age pension & average earning \\
\hline 2020 & $20.86 \%$ & $12.48 \%$ & $44.69 \%$ & $26.73 \%$ \\
\hline 2030 & $19.49 \%$ & $11.70 \%$ & $51.26 \%$ & $30.76 \%$ \\
\hline 2040 & $17.62 \%$ & $9.93 \%$ & $63.87 \%$ & $35.99 \%$ \\
\hline 2050 & $17.54 \%$ & $8.86 \%$ & $78.54 \%$ & $39.68 \%$ \\
\hline
\end{tabular}



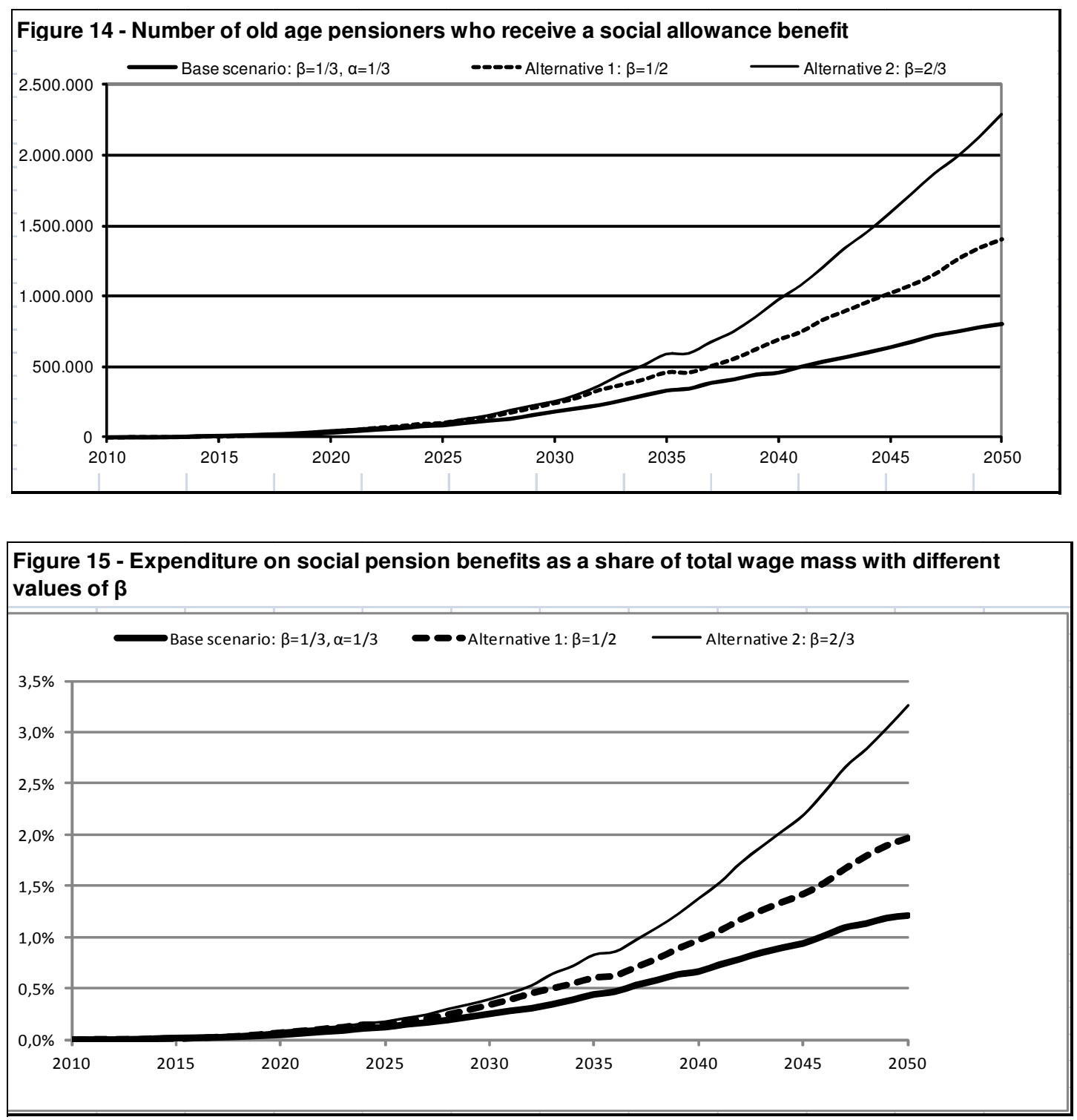

\subsection{Two other alternatives}

The conclusions of the previous section state that increasing accumulability of social assistance and NDC pensions improves both effectiveness of incentives and pension adequacy. In this section, we briefly compare our proposal with two alternatives.

Firstly, one could design a situation where the NDC system incentive problems disappear completely and adequacy substantially increases: it is when full cumulation of social assistance and NDC pensions is allowed, i.e. $\beta=1$. In such case, represented in Figure 11, shown aside with previous Figure 10, the social assistance pension, while remaining means-tested, would become a pension base, on top of which the NDC pension would add. Thus, implicit tax rates would stay at 0 and NPVRs at 1, regardless of the size of the NDC pension (Figures 11.b and 11.c).

Clearly, allowing full accumulation of the two types of pension would imply a substantial increase of public expenditure ${ }^{22}$. However, this rather extreme option should be explored together with a reduction of social contributions and an increase of fiscal revenues to finance it. Indeed, it

\footnotetext{
${ }^{22}$ An explorative simulation shows that expenditure would rise to $8 \%$ of the wage bill in 2045 and to $12 \%$ in 2050 , with more than 5 millions of individuals receiving a social assistance add-up in the last year.
} 
could and should bring-in a reassessment of the current equilibrium between the different instruments of financing the welfare. This option could even originate a reduction of labor cost and/or an increase of wages, if social assistance would end up being financed through revenues from a larger tax base than labor. While this is certainly a scenario which is worth studying more in detail, it should be noted from the beginning that a different financing arrangement would not undermine the financial equilibrium of the NDC system, which allows for the presence of noncontributory components financed through general tax revenues.

A different perspective with respect to our proposal is the one developed by Raitano and Pizzuti (Raitano 2011, Pizzuti and Raitano 2011). Wishing to address the expected fall of pension replacement rates in Italy, the authors examine a scenario where a minimum NDC pension is introduced, higher than the social assistance minimum and linked to work seniority and retirement age. The level of the minimum NDC pension would reach a maximum of 900 euro per month (2011 prices) for an individual retiring at 65 with 40 years of seniority, dropping to 710 euro per month in case of retirement at age 62 with 35 years of seniority. The amount needed to bring each NDC pension to the minimum would be financed through general fiscal revenues.

While such measure has clear positive effects on pension adequacy, which are directly proportional to its cost and depend on the exact parametric specification chosen, it is worth noting the differences with our proposal as for what is concerned with the effects on the NDC incentive structure. Indeed, while the Pizzuti and Raitano proposal increases incentives to contribute to get an higher seniority to be considered in the calculation of the minimum, it also reduces incentives to contribute above the minimum needed to get recognition for each year of work. In practice, the returns on contributions increase above that recognized in the NDC system until the yearly minimum contribution is reached, then the implicit tax rate on all additional contributions during the year becomes 1 . In other words, for those workers and pensioners that will end up benefiting from the minimum NDC pension, the DC mechanism would drop, the game becoming how large a fraction of a flat rate pension an individual will be entitled to, given her/his seniority and retirement age. Indeed, Pizzuti and Raitano do not consider such failure of the DC principle a problem, as they claim that one needs to reintroduce redistributive features within the pension system and that one has to take care of the fact that many workers with unconventional labor contracts have been subject for too many years to too little contribution rates (in order to reduce labor costs), and should not be penalized for this. We believe, however, that the reintroduction of redistributive aspects within the pension system could be done without necessarily jeopardizing the DC principle, following an approach more alike the one developed in this paper $^{23}$.

\section{Conclusions and future work}

NDC pension systems are built on principles of actuarial fairness and incentive neutrality. However, the joint consideration of NDC pensions and social assistance, means-tested, benefits like those in place in most developed countries, changes the picture considerably. Retirees entitled to a NDC pension, even in absence of other sources of income, either will not benefit, or not benefit in

\footnotetext{
${ }^{23}$ Indeed, Pizzuti and Raitano do not see their proposal as an alternative to increasing the accumulability of social assistance and NDC pensions, claiming, however, that such proposal is either not enough to address the adequacy problems (if the accumulability is not full or almost full) or that would open the door to a reduction of social contribution rates that could further endanger pension adequacy (if done on the lines shown in Figure 11).
} 
full, of social assistance, or they will get social assistance losing a part of their contributory pension. This means that, when the situation of a NDC retiree is compared to the one of somebody that never entered the public pension system, actual returns on contributions granted by NDC are lower than generally though: net present value ratios are well below 1 and, within certain intervals of the NDC pension amount, implicit marginal tax rates may reach $100 \%$.

As these problems are more pronounced at low income levels, such incentive failure of NDC system brings a regressive feature in the system that could disincentivate contribution, suggesting people to remain, or shift, into the informal sector of the economy. On this respect, NDC systems would perform even worse than traditional public DB systems, as the "old" systems rewarded work seniority and pensions awarded were typically significantly higher than social assistance.

The analysis of the current institutional framework in Italy, Sweden and Poland suggests that this issue is relevant. Thus, problems of actuarial unfairness and incentive failure in NDC systems emerge aside with the traditional concerns on pension adequacy, in particular for those at the bottom of the income distribution.

To address these issues, the paper explored the effects of increasing the possibility of cumulating social assistance and NDC pension benefits in Italy, above the current value of $1 / 3$ and to $1 / 2$ or $2 / 3$. The empirical analysis is done using CAPP_DYN, a dynamic microsimulation model of the Italian pension system. Results suggest that under the proposed reform the incentive structure and actuarial fairness would improve, as would do adequacy. According to our simulations, by rising to $1 / 2$ the parameter of accumulation of NDC and social assistance pensions would reduce the implicit tax rate from 0.67 to 0.5 , would increase the NPVR from 0.33 to 0.5 and would allow one million more pensioners than it is currently expected to benefit from a social assistance add-up on top of their NDC pension, without this endangering the public balance. Further easing the accumulation rules would further improve our indicators, but expenditure would start rising significantly.

Results presented in this paper are, till now, shown robustness with respect to changes of parameters and scenario. Further developments are envisaged in two main directions. On the one hand, it would be interesting to combine the analysis presented here with one that explicitly considers differences in life-expectancy among people with different socio-economic status. Such topic has already, although separately, been considered using CAPP_DYN, unveiling another regressive dimension of NDC systems (Mazzaferro, Morciano and Savegnago 2011). On the other hand, our parametric reform should be compared with other policy options, in particular the two alternatives considered in section 5.2, namely $i$ ) allowing full accumulation of social assistance and NDC pensions and ii) reintroducing, within the NDC system, a minimum (contributory) pension. To do this, however, one will have to make comparable the effects on incentives, on adequacy and the costs of the three options, building an appropriate metric. Also, the extreme scenario of full cumulation of the two pensions should be examined in more details, considering it in the framework of a more general rethinking of the financing of welfare expenditure. 


\section{References}

Baldini M., Mazzaferro C. and Morciano M. (2008): Assessing the Implications of Long Term Care Policies in Italy: A Microsimulation Approach. Politica Economica, No. 1/2008.

Cannon E., Tonks I. (2003): UK Annuity Rates and Pension Replacement Ratios 1957-2002. UBS Pension Research Program Discussion Paper No. 8, London School of Economics, London.

Carone G., Immervoll H., Paturot D. and Salomäki A. (2004): Indicators of Unemployment and Low-Wage Traps (Marginal Effective Tax Rates on Employment Incomes). Social, Employment and Migration Working Papers, n. 18. OECD, Paris.

Chlon-Dominczak A., Strzelecki P. (2010): The Minimum Pension as an Instrument of Poverty Protection in the Defined Contribution Pension System - An Example of Poland. MPRA Paper No. 25262. http://mpra.ub.uni-muenchen.de/25262/.

Department of General Accounts (2011): Mid-long term trends for the pension, health and long term care systems. Ministry of economy and finance, Rome.

Employment Committee (2003): Making Work Pay. European Union, Bruxelles.

Estelle J., Song S. (2001): Annuities Markets Around the World: Money's Worth and Risk Intermediation. WP CeRP n. 16-2001, Turin.

Guazzarotti G., Tommasino P. (2008): The Annuity Market in an Evolving Pension System: Lessons from Italy. CeRP WP No. 77, Turin.

Holzmann R., E. Palmer (eds.) (2006): Pension Reform. Issues and Prospects for NonFinancial Defined Contribution (NDC) Schemes. World Bank, Washington DC. http://siteresources.worldbank.org/INTPENSIONS/Resources/NDC_English.pdf.

Istat (Istituto nazionale di statistica) (2011): I Beneficiari delle Prestazioni Pensionistiche. Rome. http://www.istat.it/sanita/assistenza/.

Mackenzie G., Schrager A. (2004): Can the Private Equity Market Provide Secure Retirement Income? IMF WP 04/230, Washington D.C.

Mazzaferro C., Morciano M., Savegnago M. (2011): Differential Mortality and Redistribution in the Italian Notional Defined Contribution System. Journal of Pension Economics and Finance, forthcoming.

Marano A. (2006): Pension Reforms in Italy: Principles and Consequences. Revue française des affaires sociales, n. 1/2006, Paris.

Mazzaferro C., Morciano M. (2011): CAPP_DYN: A Dynamic Microsimulation Model for the Italian Social Security System. Mimeo.

Mazzaferro C., Morciano M. (2011): Measuring Intra-Generational And Inter-Generational Redistribution In The Italian Old Age Pension System. Mimeo.

OECD (2007): Pension at a glance 2007. OECD, Paris.

Pizzuti R., Raitano M. (2011): Le Prospettive del Sistema Previdenziale: Problemi e Proposte. In: R. Pizzuti (ed.): “Rapporto sullo stato sociale 2011”. Esselibri, Naples, pp. 388-398.

Queisser M., Whitehouse E. R. (2006): Neutral or Fair? Actuarial Concepts and PensionSystem Design. OECD Social, Employment and Migration Working Papers, No. 40, OECD, Paris. www.oecd.org/els/workingpapers.

Raitano M. (2011): Carriere fragili e pensioni attese: $i$ possibili correttivi al sistema contributivo e la proposta di una pensione di garanzia. Rivista delle politiche sociali, n. 3. Ediesse, Rome. 
Social Protection Committee (2009): Updates of Current and Prospective Theoretical Replacement Rates - 2006-2046. Report of the Indicator Subgroup. Annex: Country Fiches. European Union, Bruxelles. http://ec.europa.eu/social/main.jsp?langId=en\&catId=752\&newsId=551\&furtherNews=yes.

TARKI Social Research Institute (2009): PENMICRO - Monitoring Pension Developments through Micro Socioeconomic Instruments based on Individual Data Sources: Feasibility Study. Final Report for The European Commission. European Union, Bruxelles. http://ec.europa.eu/social/main.jsp?langId=en\&catId=89\&newsId=490\&furtherNews=yes.

Whitehouse E. R. (2010): Decomposing National Defined-Contribution Pensions: Experience of OECD Countries' Reforms. OECD Social, Employment and Migration Working Papers, No. 109, OECD, Paris. www.oecd.org/els/workingpapers. 


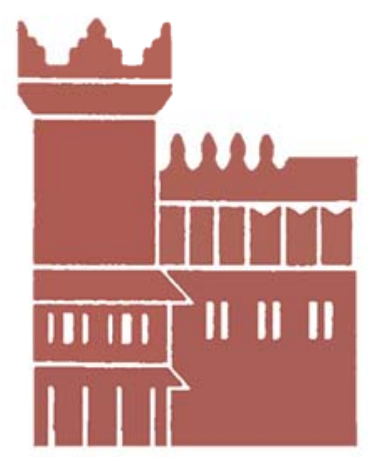

Alma Mater Studiorum - Università di Bologna DEPARTMENT OF ECONOMICS

Strada Maggiore 45

40125 Bologna - Italy

Tel. +39051 2092604

Fax +390512092664

http://www.dse.unibo.it 